\title{
EXPERIÊNCIAS JUVENIS EM ESPAÇOS URBANOS: A INFLUÊNCIA DO CONTEXTO ESCOLAR
}

\author{
BRUNO GUILHERMANO FERNANDES ${ }^{1}$
}

\begin{abstract}
RESUMO
Este escrito apresenta resultados de um estudo, de abordagem qualitativa, que promoveu a análise de discursos e práticas de estudantes secundaristas de uma escola pública, inseridos em um recorte urbano de Porto Alegre/RS. 0 foco do artigo está em captar, sistematizar e comunicar determinadas experiências de jovens, moradores de regiões periféricas, para pôr em relevo como as mesmas estão sendo configuradas não apenas pelo vínculo pedagógico e de caráter social com 0 espaço escolar, mas, também, pelas marcas da segregação social e desigualdade urbana. Complementarmente, a partir de suas maneiras de habitar a cidade, é possível apreender algumas percepções sobre as suas formas de mobilidade, estratégias de ascensão e tentativas de reversão de estigmas territoriais associados aos seus locais de moradia.
\end{abstract}

\section{PALAVRAS-CHAVE}

Experiências Juvenis; Educação Escolar; Espaços Urbanos; Desigualdade urbana.

\section{YOUTH EXPERIENCES IN URBAN SPACES: THE INFLUENCE OF THE SCHOOL CONTEXT}

\begin{abstract}
This paper presents the results of a study, with a qualitative approach, which promoted the analysis of discourses and practices of the high school students at a state public school, situated in an urban context of the Porto Alegre city, south of Brazil. The focus of the article is to capture, systematize and communicate certain experiences of young people, residents in peripheral regions, to highlight how they are being configured not only by the pedagogical and social link with the school space, but also by the marks of social segregation and urban inequality. Complementarily, from their ways of inhabiting the city, it is possible to apprehend some perceptions about their forms of mobility, ascension strategies and attempts to reverse territorial stigmas associated with their places of residence.
\end{abstract}

\section{KEYWORDS \\ Youth Experiences; School Education; Urban Spaces; Urban inequality.}

\section{EXPÉRIENCES DES JEUNES DANS LES ESPACES URBAINS: L'INFLUENCE DU CONTEXT SCOLAIRE}

\section{RESUMÉ}

Cet article présente les résultats d'une étude, avec une approche qualitative, qui promeut l'analyse des discours et des pratiques des lycéens d'une école publique, inséré dans une zone urbaine de la ville de Porto Alegre, sud du Brésil. L'objectif de l'article est de capturer, systématiser et communiquer les expériences des jeunes, résidents des régions périphériques, pour mettre en évidence comment elles sont configurées non seulement par le lien pédagogique et social avec l'espace scolaire, mais aussi par les marques de la ségrégation social et inégalités urbaines. De manière complémentaire, à partir de leurs manières d'habiter la ville, il est possible d'appréhender certaines perceptions sur formes de mobilité, les objectifs d'ascension et le inverser des stigmates territoriaux associés à leurs lieux de résidence.

\footnotetext{
${ }^{1}$ Professor e pesquisador. Licenciado em Ciências Sociais (UFRGS) e técnico em Gestão Cultural (IFSul). Mestrando no Programa de Pós-Graduação em Antropologia Social - Museu Nacional/UFRJ.
} 


\section{MOTS-CLÉS}

Expériences des jeunes; Éducation scolaire; Espaces urbains; Inégalités urbaines.

EXPERIENCIAS JUVENILES EN ESPACIOS URBANOS: LA INFLUENZA DEL CONTEXTO ESCOLAR

\section{RESUMEN}

Este artículo presenta los resultados de un estudio, con enfoque cualitativo, que promovió el análisis de discursos y prácticas de estudiantes de enseñanza secundaria en una escuela pública, ubicada en un recorte de la ciudad de Porto Alegre, región sur de Brasil. El enfoque del artículo es capturar, sistematizar y comunicar ciertas experiencias de los jóvenes, residentes de regiones periféricas, para resaltar cómo ellas están siendo configuradas no solo por el vínculo pedagógico y social con el espacio escolar, sino también, por las marcas de la segregación social y de la desigualdad urbana. Complementariamente, a partir de sus maneras de habitar la ciudad, es posible aprehender algunas percepciones sobre sus formas de movilidad, estrategias de ascensión e intentos de revertir los estigmas territoriales asociados con su lugar de vivienda.

\section{Palabras ClaVe}

Experiencias juveniles; Educación escolar; Espacios urbanos; Desigualdad urbana. 


\section{INTRODUÇÃO}

O presente trabalho teve, como ponto de partida, a inspiração obtida a partir da experiência de estágio docência no curso de Licenciatura em Ciências Sociais, realizado durante o ano de 2018, em uma escola pública estadual de Porto Alegre/RS. Após essa primeira experiência, a pesquisa foi continuada em 2019, resultando em trabalho de conclusão de curso específico em torno das conexões entre juventudes, educação escolar e cidade (FERNANDES, 2019)².

Deste modo, a partir da pesquisa ensejada, busquei trabalhar analiticamente com diferentes experiências juvenis, privilegiando, a partir do contexto escolar, evidenciar algumas de suas relações com e em espaços urbanos. Significou, à ocasião, refletir sobre as experiências de jovens a partir suas redes de sociabilidade, tramas e expressões simbólicas, vínculos com grupos e instituições, performances individuais e trajetórias, as quais podem ser consideradas como marcadas pela desigualdade urbana e socioeconômica existente.

Neste sentido, o interesse deste escrito é apresentar um recorte de resultados desse estudo, de abordagem qualitativa, que promoveu a análise de discursos e práticas atreladas às diferentes expressões e trajetórias de estudantes secundaristas de uma escola pública, inseridos em um recorte urbano de Porto Alegre/RS. Posso delinear, inicialmente, que o foco deste registro está em captar, sistematizar e comunicar determinadas experiências que delineiam as trajetórias de jovens, para pôr em relevo como as mesmas estão sendo configuradas não apenas pelas marcas da segregação social e desigualdade urbana. Estão, também, constantemente ressignificadas pelo trabalho pedagógico, técnico, ético e político realizado no contexto escolar.

Complementarmente, a pesquisa que embasa este texto aposta no esforço de compreensão das formas de interação, dos usos e apropriações do espaço urbano, seja nos interstícios da vida institucional escolar, ou fora dela (CERTEAU, 1990). Significa efetuar, em outros termos, uma narrativa que tenta visibilizar a percepção das diferentes maneiras de operar e praticar relações com e na cidade, engendradas pelos jovens, sobretudo estudantes secundaristas.

\footnotetext{
${ }^{2}$ O Trabalho de Conclusão de Curso foi intitulado "Experiências Juvenis e Espaços Urbanos: relações a partir do contexto escolar", defendido em 2019, sob orientação do professor e antropólogo Eduardo Dullo, na Universidade Federal do Rio Grande do Sul (UFRGS). Agradeço a ele pelas contribuições significativas durante toda a pesquisa. O trabalho encontra-se disponivel no portal LUME da UFRGS: <https://www.lume.ufrgs.br/handle/10183/212952>.
} 


\section{COMO IDENTIFICAR EXPERIÊNCIAS JUVENIS NA CIDADE A PARTIR DA ESCOLA?}

Evidentemente, a escola congrega uma diversidade de atores sociais e, por consequência, é um local imponderável de reprodução e de modificação das chamadas "culturas juvenis" (FEIXA, 1998; MAGNANI, 2005; PEREIRA, 2010).

Nos últimos anos, é de amplo conhecimento que o espaço escolar passou a ser pesquisado a partir do emprego de recursos metodológicos de abordagem qualitativa, reunindo uma diversidade de técnicas oriundas das ciências humanas (MOREIRA, 1990; OLIVEIRA; BOIN; BÚRIGO, 2018). No bojo da imersão etnográfica, tal como sugere Amurabi Oliveira et al. (2018), evitando a simples redução de sujeitos em objetos de pesquisa, notamos como a escrita etnográfica se esforça para capturar processos de interação e sociabilidades (e, especialmente, socialidades), que produzem a própria realidade escolar e que poderiam não ser priorizados em outras abordagens.

Nesta perspectiva, evidenciamos que a etnografia em contextos escolares pode pôr em relevo experiências juvenis conectadas às mais diferentes realidades e que estão inseridas em espaços urbanos (MAGNANI, 2002; GOLDMAN, 2006; PEREIRA, 2010). Com este intuito, busco relacionar respostas às seguintes questões, neste artigo: A) Por que pensar as experiências juvenis a partir de espaços escolares? B) Por que determinados jovens frequentam uma escola localizada em uma região central e não nas regiões periféricas? C) Quais são as suas estratégias de mobilidade urbana e o que elas comunicam? D) Como seus deslocamentos, a partir da necessidade de frequentar a escola, influenciam as suas percepções sobre a cidade habitada?

Para tentar responder a essas questões, recorro, igualmente, a alguns recursos metodológicos. Além da pesquisa em fontes documentais, o recurso ao método etnográfico foi viabilizado, o que implicou na realização de um trabalho de campo assentado no emprego de duas técnicas: a de observação participante, viabilizada a partir da experiência de estágio docência disciplinar em Sociologia com o ensino médio noturno, sobretudo durante o ano de 2018; e na realização de entrevistas semi-estruturadas com estudantes secundaristas e docentes do contexto estudado, ao longo do primeiro semestre de 2019 (a partir do consentimento dos responsáveis, quando menores, e da garantia de preservação de suas identidades).

No âmbito das referidas entrevistas, pontos centrais para a discussão em torno do problema de pesquisa foram questionados aos estudantes participantes, tais como: relações com os locais de moradia, trabalho e estudo e percepções sobre os espaços urbanos; formas e estratégias de mobilidade; visões sobre a segurança e insegurança nos deslocamentos pela cidade; dinâmicas internas da escola; dentre outros aspectos. O uso de entrevistas possibilitou uma análise dos conteúdos a partir dos temas propostos. Ao todo, oito (08) 
entrevistas com jovens foram viabilizadas ${ }^{3}$, sendo três delas com estudantes do ensino médio diurno e cinco do noturno - todos moradores de Porto Alegre/RS.

Por uma questão ética, a identidade dos interlocutores foi mantida em sigilo e, ao longo das análises, suas identificações aparecem substituídas por nomes fictícios. Ao final, a análise foi articulada com fundamentação teórica atinente às discussões sobre as relações da juventude com o universo escolar e com os espaços urbanos, sobretudo nos campos de antropologia da juventude, da educação escolar e de sociologia urbana. Em termos estilísticos, a abordagem polifônica adotada por Paul Willis (1991) - em seu estudo clássico sobre as relações entre escola, trabalho e reprodução social - foi empregada como inspiração, à forma como as análises são articuladas neste trabalho.

Convém situar que uma escola pública estadual, situada em Porto Alegre/RS, serviu como o contexto escolar e urbano que foi o lócus de minha observação e, antes, de observação e atuação durante o estágio docência. O foco, neste aspecto, direcionou-se ao contexto do Instituto Estadual Rio Branco", particularizado como uma espécie de "laboratório da vida social juvenil", para fins analíticos. A escola está situada em uma zona considerada central na cidade referida, na Avenida Protásio Alves, a qual conecta a sua região central com bairros periféricos. Avizinha-se, ainda, por uma escola particular: o Colégio Israelita ${ }^{5}$.

Comumente, a escola emerge como um lugar especializado e disciplinado para a construção de um novo tipo de sujeito, sendo "originariamente um espaço de confinamento de crianças para a instrução, esclarecimento e civilização", o qual serviu para a produção de normas, disposição de corpos e controle de tempos e espaços conforme as atividades e necessidades educativas e disciplinares de cada época (NOGUEIRA-RAMÍREZ, 2011).

A escola, desta forma, pode ser lida como um dispositivo educacional destacado pela sua carga simbólica e pelo seu caráter disciplinar - efetuando, até mesmo, práticas sociais concretas à sua administração panóptica. Mas tal entendimento não encerra (e é um equívoco etnográfico encerrar) as possíveis compreensões em torno do espaço escolar.

\footnotetext{
${ }^{3}$ Os dados e marcadores sociais em torno dos entrevistados foram analisados mais detidamente no "capítulo 5" do trabalho de conclusão de curso já mencionado (FERNANDES, 2019). Além das oito entrevistas com estudantes, foram realizadas mais duas com docentes da mesma escola.

${ }^{4}$ O Instituto Estadual Rio Branco (IERB) foi fundado em 1930, na esquina da Avenida Protásio Alves (antigo "Caminho do Meio") com a Rua São Vicente. Curiosamente, essa escola pública estadual possui o mesmo nome do bairro vizinho ao bairro de sua referência (Rio Branco), mas está localizada nos limites do bairro Santa Cecília, nas proximidades de zonas centrais de Porto Alegre/RS. Registros obtidos na escola aludem ao fato de que o nome "Rio Branco" foi escolhido, na década de 30, em homenagem ao escritor e patrono da diplomacia brasileira Barão do Rio Branco.

${ }^{5}$ A "imagem 1" expõe uma contradição evidente: embora a parada de ônibus ganhe o nome da instituição de ensino particular, os que mais frequentam e ocupam este recorte espacial são os próprios jovens da escola pública estadual, fluxo cotidiano que acentua a sua caracterização enquanto "escola de passagem".
} 
Os dispositivos planejados e materializados no espaço, situados no bojo da geografia política de uma cidade, estimulam a configuração de relações específicas, através do reconhecimento de lugares estratégicos à manifestação de identidades plurais e à constituição de sociabilidades diversas. Embora comumente demarcado, em termos territoriais, por muros, cercas, ou até mesmo com arames farpados (e toda a sua potência repulsiva), o ambiente escolar torna-se perceptível, de igual modo, mediante os fluxos e as características que permite identificar.

Imagem 1. Estação "Colégio Israelita”, na Avenida Protásio Alves. Ao lado direito, na esquina e cercado por um muro amarelo, encontra-se o Instituto Rio Branco, situado ao lado do colégio referido, após a faixa de segurança (recortado da imagem).

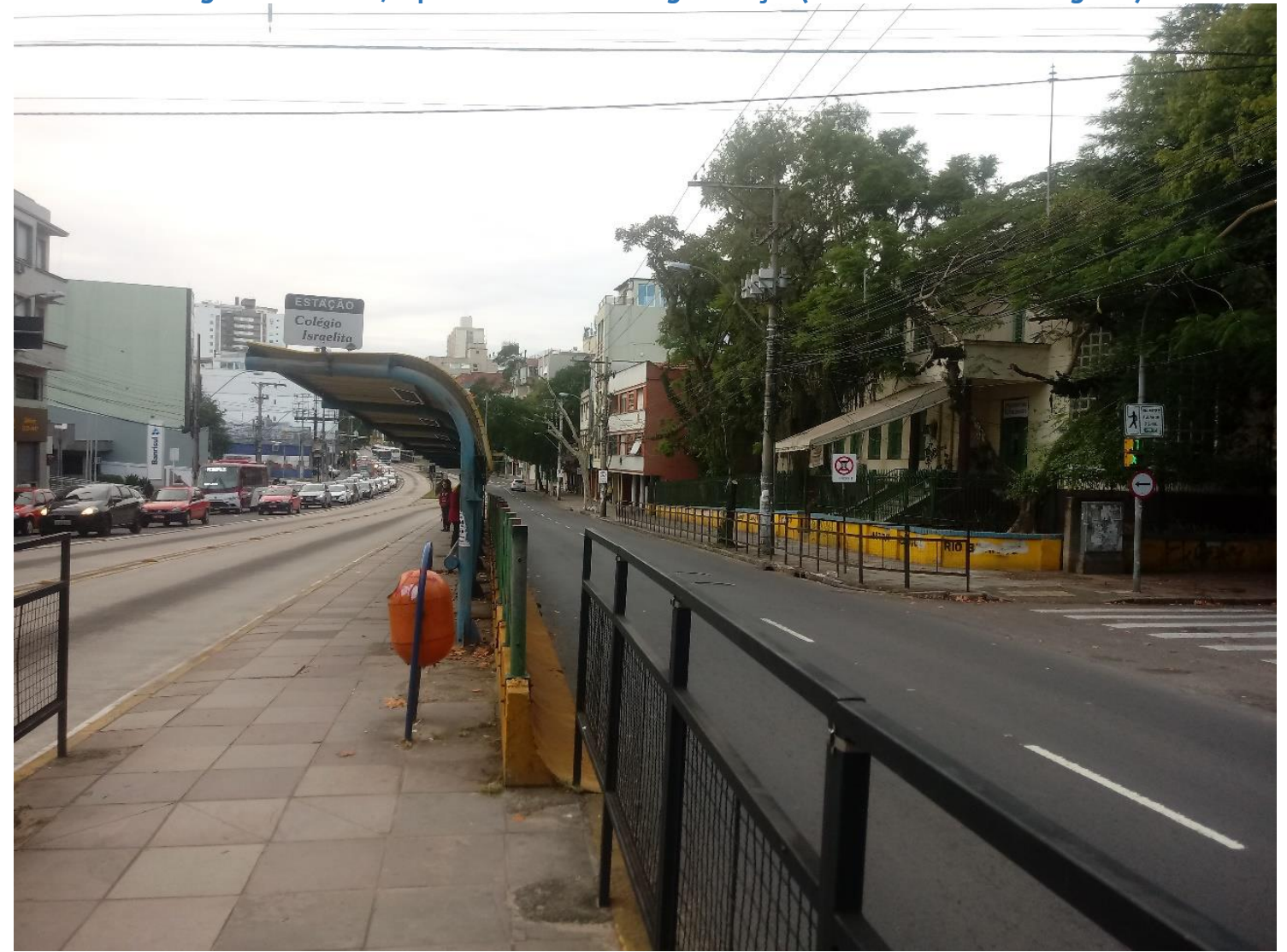

Acervo do autor, 2019

\section{POR QUE PENSAR AS EXPERIÊNCIAS JUVENIS A PARTIR DA ESCOLA?}

Categoricamente, é possível considerar a escola como um espaço privilegiado de observação participante e de intervenção reflexiva, perspectiva também influenciada por trabalhos de cientistas sociais que pesquisaram o campo da educação escolar (WILLIS, 1991; DUBET, 1997; FONSECA, 1999; DAYRELL, 1996; 2003; SCHWEIG, 2015; SEFFNER, 2016; PEREIRA, 2017). Ou, em termos políticos, como representante de uma política pública, engendrada no âmbito da heterogeneidade do Estado e de sua administração tecnocrática e panóptica (FOUCAULT, 1987; CERTEAU, 1990). 
Em tese específica sobre experiências juvenis contemporâneas observadas em diferentes contextos escolares e etnográficos, situados nas periferias de São Paulo/SP, o antropólogo Alexandre Barbosa Pereira (2010) procurou demonstrar diferentes maneiras de como as vivências juvenis eram modificadas e modificavam outras experiências, como as escolares e as de cunho tecnológico, acompanhadas por componentes lúdicos.

Para o autor, há, na relação entre jovens e âmbito escolar, uma dupla definição: a escola cria uma "sociedade adolescente" pela separação e agregação dos jovens em um espaço de relacionamento em comum. Por outro lado, os estudantes adolescentes também reinventam a própria noção de escola, a partir de apropriações feitas por práticas da juventude, que alteram as dinâmicas escolares (PEREIRA, 2010). Tal trabalho etnográfico apresenta um potencial analítico para a reflexão em torno da imbricação juventude-escola. Porém, não deixa de realizar a crítica sobre o distanciamento evidente de muitas das instituições escolares com seus entornos, já que, na maioria das vezes, as escolas públicas atendem crianças e jovens dos locais em que se inserem, mas de modo distanciado da realidade deles e de suas comunidades.

Seguindo a perspectiva lançada por Philippe Ariès (1978), o antropólogo mencionado concorda com o segundo que o espaço escolar possui papel fundamental para a compreensão do conceito de juventude como uma espécie de construção sócio-histórica. Ambos acentuam que, no contexto pós-idade média, a escola permitiu que a infância fosse separada da vida adulta, gerando um corte e respectivo "enclausuramento" concebido como escolarização (ARIÈS, 1978; PEREIRA, 2010).

Esta separação, gerada por uma suposta reclusão disciplinarizadora, teria sido central para demarcar a força política e o caráter social com a qual as categorias de "infância" a de "juventude" teriam surgido ao longo do tempo, no processo de ocidentalização de sociedades coloniais. Com efeito, o argumento que os autores trabalham é o de que a escola ainda continua a inventar e a reinventar as noções de "infância" e de "juventude", porém, atualmente, ocorreria também um processo inverso. Em decorrência disso, os jovens e as crianças, "que foram isolados desde o início dos tempos modernos para passarem por um período de formação moral e intelectual separado da sociedade dos adultos", estariam recriando o espaço escolar com suas novas demandas e práticas, atreladas aos mais diversos estilos de vida e com necessidades variadas - geracionais, tecnológicas, interseccionais etc. (PEREIRA, 2010, p. 11).

No contexto da modernidade ocidental, emerge a noção da escola como uma "invenção cultural", apresentando uma forma implantada em ampla escala e com pouca variabilidade (apesar de se situarem em diferentes localidades), tendo em vista que preserva a institucionalização de diferentes mecanismos disciplinares e espaciais (PEREIRA, 2010, p. 83). Contudo, apesar da padronização de formas institucionalizadas de ensino, 
disciplinamento e gestão, há de se considerar que cada estabelecimento possui, também, suas próprias peculiaridades, fluxos e dinâmicas fundamentais.

No caso do Instituto Estadual Rio Branco (IERB), chamou-me a atenção o fato de esta instituição contar, nos seus três diferentes turnos, com 1.323 alunos matriculados em 2018 - com o Ensino Médio totalizando 758 matrículas ${ }^{6}$. Um aspecto, em torno dos matriculados, ressaltado por vários interlocutores, é o de que um número considerável de estudantes reside em diferentes localidades periféricas, sobretudo na zona leste de Porto Alegre/RS. É representativo o fato, capturado em observações sistemáticas, de que muitos residem em outros bairros da cidade, principalmente em suas zonas periféricas, comumente associadas com representações e imagens de violência e de degradação, moduladas por veículos midiáticos e agentes políticos externos.

Em outros termos, muitos jovens habitam zonas urbanas que podem ser entendidas como "deserdadas", na chave analítica proposta por Loïc Wacquant (2006), isto é, regiões marcadas pela ausência de medidas e de serviços estatais eficientes (para além da ação penal-policialesca) e moduladas pelo estigma territorial em relação às demais partes da cidade. Como sugere o autor referido, a percepção de novos regimes de "marginalidade urbana" em zonas periféricas de grandes centros urbanos pode ser refletida etnograficamente ${ }^{7}$.

Seria um equívoco analítico, no entanto, considerar o ensino médio do Instituto Rio Branco como um universo escolar ocupado e habitado apenas por jovens e adultos que reproduzem ali práticas que remontam à inseguridade e à violência urbana que vivenciam. Seria a confirmação de uma leitura promotora de estereótipos e da estigmatização de seus pertencimentos territoriais. Logo, àquele contexto escolar, ocupado pelo público mencionado, não pode ser lido enquanto uma "escola de risco" (ou, como se convencionou

\footnotetext{
${ }^{6}$ Dados disponíveis por etapas da educação básica em: <https://www.qedu.org.br/escola/233549-ieriobranco/sobre>.

${ }^{7}$ A partir de dados etnográficos e fontes documentais sobre os "guetos americanos" e o subúrbio operário francês, Wacquant (2006) traduz como os chamados "desviantes" da metropóle pósindustrial estão associados aos territórios isolados e circunscritos, todavia percepcionados na paisagem urbana. Quando estes "espaços penalizados" começam a se tornar evidentes em zonas que compõem os cinturões periféricos das cidades, os discursos que atestam seu descrédito amplificam-se e aglomeram-se à sua volta, veiculados nas interações da vida cotidiana e propagados pelos domínios jornalísticos, políticos, burocráticos e até mesmo científicos. Sobreposta aos estigmas existentes, ligados à pobreza e ao pertencimento étnico-racial, uma mácula localizada permearia os discursos e imaginários sociais que incidem sobre esses bairros. A proposta de Wacquant possibilita a reflexão sobre os imaginários conectados com determinados espaços, associados à conformação de formas de pobreza e de criminalidade, que são inscritas nas dinâmicas de sociedades neoliberais. Estas, por sua vez, se alimentam da desintegração da condição dos assalariados, da relegação de bairros deserdados (não priorizados pelo poder público e setor privado), de tendências macroeconômicas e da reconfiguração de um modelo polarizado de cidade (entre zonas centrais e zonas periféricas). Logicamente, o emprego do aporte teórico em questão implica a consideração das especificidades de cada contexto e localidade.
} 
chamar no contexto português, uma "escola do diabo"), nos termos de José Machado Pais (2008) - um entendimento limitado e simplificador.

Ainda que a maioria dos jovens e adultos seja proveniente de bairros periféricos, populosos e economicamente caracterizados por populações de baixa renda, comecei a notar as presenças de muitos deles na escola mediante formas estratégicas e táticas de compor territórios e relações distintas - simbólicas e materiais - das que estão marcadas pelas redes de inseguridade, violência e de degradação urbana das zonas em que residem. Рага exemplificar, cito uma conversa relevadora, que tive em 2018 com um aluno, jovem e negro de 23 anos, na porta de saída da escola, antes do horário de término do turno escolar noturno. Na ocasião, pouco antes das 21 horas, ele me afirmou que estaria indo mais cedo para casa devido aos conflitos armados em seu bairro, ou "vila" - categoria que, por vezes, é alternada pela noção de "periferia". Em sua região de moradia, relatou-me que facções armadas estariam disputando mercados ilícitos (reproduzindo o intenso tráfico de drogas e de armas) e seu retorno tardio a casa poderia intensificar uma inseguridade que sentia ao circular nas ruas próximas de sua moradia. Ele afirmou: "professor, ontem mataram um cara lá num beco perto de casa no final da noite, por isso estou voltando mais cedo". Apenas consenti, em resposta, manifestando a necessidade de que ele devesse tomar cuidado, mesmo ciente de que ele dominava códigos de proteção, noções locais de autoridade e compunha táticas específicas para circular naquele mesmo território. O período de 2016 até 2018 foi marcado pelas chamadas "guerras entre facções" em Porto Alegre e por suas implicações com o aumento de taxas de letalidade, a partir de uma disputa aberta por territórios e mercados ilícitos (CIPRIANI, 2019; BARROS, 2020).

Por outro lado, a presença dos jovens na escola conforma sensibilidades, modos de se portar e estilos de vida (uma espécie de éthos), os quais buscam reverter percepções de determinados caracteres pejorativos, ou seja, promovendo imagens positivas de seus territórios de moradia e refazendo criticamente as imagens estigmatizadas sobre as periferias (PEREIRA, 2010).

De modo complementar, a presença deles naquela escola ampliava o repertório de possibilidades de usos programados e não programados (contra-usos) dos espaços urbanos e das redes de sociabilidade que podem compor, para além dos bairros e zonas que moram (CERTEAU, 1990). Mais do que uma "escola de passagem" ${ }^{8}$ composta por um público heterogêneo, o Instituto Rio Branco é reconhecido, também, enquanto um espaço de referência para os estudantes que buscam (re)conhecer a cidade. Fundamentalmente, as

\footnotetext{
${ }^{8}$ Expressão que escutei em diferentes ocasiões, dita pelos professores e alunos, para se referir à transitoriedade dos fluxos na escola: por um lado, por estar situada em uma avenida movimentada e de amplitude urbana; por outro, por ser frequentada por parcela de jovens que conciliam estudo, trabalho e lazer. A mesma evidência é encontrada no trabalho de Laurence Aquino (2016).
} 
experiências juvenis com aquela escola comunicam percepções sobre a cidade, sobretudo em torno de suas dinâmicas e desigualdades.

A partir do caso supracitado, pontuo, de outro modo, que linhas de força produzidas socialmente colaboram para o fato de que "jovens com idades iguais vivem juventudes desiguais" (NOVAES, 2006, p. 105). Esta é a perspectiva ensejada pela cientista social Regina Novaes, ao escrever sobre como determinados marcadores sociais incidem nas diferentes maneiras de se experenciar a juventude. Em seu escrito, infere que o conceito de "juventude", concebido histórica e culturalmente, está circunscrito por definições que refletem disputas nos campos de poder político e econômico e, também, desvelam conflitos "entre e intragerações".

Desta forma, os sentidos para a pergunta "o que é ser jovem?" vêm sendo modificados ao longo do tempo, gerando possibilidades distintas para se analisar as trajetórias de jovens brasileiros. Assim, à autora referida, traçar limites de idade para definir uma faixa etária que conforme, biologicamente, quem pode ser jovem apresenta certa inconsistência, tendo em vista que: "(...) para os que não têm direito à infância, a juventude começa mais cedo". E, "no outro extremo - com o aumento de expectativas de vida e as mudanças no mercado de trabalho -, uma parte deles acaba por alargar o chamado "tempo da juventude" até a casa dos 30 anos" (NOVAES, 2006, p. 105).

No âmbito da desigualdade identificada por um "tempo de ser/estar jovem", podemos começar a perceber como marcadores sociais diferenciados - como, por exemplo, classe social, raça, gênero e lugar de origem, ou de moradia - fazem diferença na conformação de arranjos sociais e de possibilidades para se "viver a juventude". O que me parece interessante, na reflexão proposta por Regina Novaes (2006), é a identificação que mesmo todos esses aspectos citados não esgotam o diferenciado mosaico que podemos chamar de "juventude brasileira". As disparidades regionais e as relações entre campo e cidade - urbano e rural - devem ser consideradas para algum eventual diagnóstico, tendo em vista que as diferenças e as particularidades locais podem "atenuar ou acentuar algum dos vários vetores que produzem e/ou reproduzem as desigualdades sociais" (NOVAES, 2006, p. 107). E mais, me faz pensar que, no âmbito de uma única cidade, existem diferenciações urbanas que dinamizam os matizes da situação juvenil - refletidas, por lógica, nos mais variados contextos escolares.

A partir desta reflexão, noto como, além de todos os fatores e marcadores referidos, as experiências juvenis podem estar conectadas, também, com dinâmicas escolares e com processos de mobilidade das diferentes regiões que compõe uma cidade. Entretanto, ao contrário do que a ordem dominante preconiza, os usos do espaço escolar (que também é um espaço na urbe) não estão dados, o que nos relembra que as maneiras de praticar e de utilizar o espaço podem fugir dos objetivos almejados pela "planificação 
urbanística" (CERTEAU, 1990). Evidentemente, tal dimensão se estende, também, para as relações tecidas entre juventude e espaços escolares urbanos ${ }^{9}$.

A compreensão acerca das relações de estudantes secundaristas com e nos espaços urbanos trouxe, como desafio, a interlocução aprofundada com os jovens, de modo a priorizar a análise de suas narrativas e práticas.

Para este empreendimento, tomei como ponto de partida algumas contribuições teóricas, dentre elas a de um autor que possibilita a reflexão em torno dos usos plurais e formas de praticar e habitar os espaços planejados de uma cidade: Michel de Certeau. Em sua clássica obra "A invenção do cotidiano" (1990), o autor busca tratar, com proeminente originalidade, das chamadas "práticas", ou "maneiras de fazer cotidianas", isto é, de modos plurais de operar e atuar daqueles que usam, consomem, ou se movimentam taticamente por espaços sociais dominados por diferentes estratégias de subordinação (CERTEAU, 1990, p. 38).

Assim, aqueles que praticam a cidade e habitam seus espaços planejados (seus usuários e consumidores), utilizam-na em formas específicas e cotidianas, combinando modelos de ação característicos com seu estatuto de "dominados" com modelos não planejados, o que não caracteriza uma mera docilidade (adaptação ao desigual regime de forças) diante dos espaços formulados por alguma racionalidade tecnocrática (ou forma de sujeição absoluta às tecnologias disciplinares e panópticas).

A análise de Michel de Certeau (1990) focaliza as práticas cotidianas para dar ênfase aos usos e consumos que os sujeitos (pessoas influenciadas por múltiplas relações e fluxos (extra)ordinários) realizam de diferentes objetos sociais, como, por exemplo, de representações, comportamentos, bens de consumo e espaços concebidos. Trata-se de levar a sério aquilo que as pessoas fazem, fabricam, manobram e operam a partir do que consomem e manipulam - dimensão que nem sempre tem relação direta com a finalidade prévia, instituída e atrelada ao planejamento do objeto manipulado.

\footnotetext{
${ }^{9}$ Para elucidar o aspecto apontado - da alteração promovida no espaço escolar pela juventude pelo emprego de novas tecnologias - cito uma situação que emerge como constructo etnográfico. Em minhas observações, notei o exemplo de um aluno do $3^{\circ}$ ano que, astuciosamente, levava para a escola, uma caixa de som portátil para executar músicas, a partir da tecnologia bluetooth do seu aparelho celular. Durante alguns intervalos das aulas do ensino médio noturno, se utilizava daqueles aparelhos para "animar" os demais colegas. As músicas tocadas - sobretudo dos musicais Rap e Funk - revelavam não apenas certo éthos daquele estudante (que conjuga valores e modos específicos de se portar e de comunicar sua existência), mas, também, alterava a dinâmica de relações e sociabilidades na escola. Todos acabavam sendo "afetados" pelo som, dentro e fora das salas de aula (inclusive, na sala dos professores!), o que denunciava a presença do componente lúdico e tecnológico naquele ambiente. Ao longo do ano, a supervisão escolar decidiu fomentar um Sarau, organizado pelos estudantes e envolvendo a atividade musical descrita. Trata-se de um exemplo expressivo: ao invés de demarcar a defasagem entre o cotidiano escolar e as novas tecnologias reprimindo o uso do aparelho -, a situação revelou que novas sensibilidades juvenis têm sido fundamentais à alteração das dinâmicas escolares de interação - em outros termos, sugere, também, que a tecnicidade pode ser central para a compreensão de como as subjetividades juvenis são atualmente produzidas - dimensão trabalhada por Alexandre Pereira (2010).
} 
Em outros termos, torna-se relevante perceber que os consumidores, usuários de uma cidade, fazem diferentes usos dos produtos que lhes são impostos, numa espécie de "bricolagem" que nem sempre é captada, identificada, ou até mesmo controlada pelas redes de "vigilância" das tecnologias disciplinares existentes nos diferentes espaços sociais citadinos. Diante disso, uma análise em torno das "maneiras de operar" dos usuários de uma cidade resulta no reconhecimento da formalidade em torno das "artes de fazer", engendradas pelos praticantes através de atividades articuladas a uma ordem dominante, porém atreladas a uma "inventividade artesanal". À luz de Michel de Certeau (1990), foi possível captar maneiras de habitar a cidade, ensejadas pelos interlocutores da pesquisa.

\section{POR QUE DETERMINADOS JOVENS FREQUENTAM UMA ESCOLA LOCALIZADA EM UMA REGIÃO CENTRAL E NÃO NAS REGIÕES PERIFÉRICAS?}

Como ponto de partida, considerando a escola como contexto de interação e espaço social comum entre todos os entrevistados, busquei identificar as suas percepções em torno dos deslocamentos cotidianos entre o local de moradia e o local de estudo. Durante as entrevistas, principiei questionando se os jovens consideravam residir próximos ou distantes do local de estudo e quais vantagens e desvantagens de sua situação. As respostas revelaram uma convergência: a percepção de distância dos jovens sobre morar distantes ou afastados da instituição escolar depende, fundamentalmente, do tempo de deslocamento e do meio de transporte que empregam para tanto.

Рага alguns interlocutores, "morar longe" significa ficar muito tempo em condução, realizando o trajeto de casa à escola, ou ficar "muito tempo esperando o ônibus", como relatou Vanessa (estudante do $2^{\circ}$ ano noturno, 17 anos, autodeclarada mulher parda e residente no bairro Bom Jesus). No caso de Paulo (estudante do $2^{\circ}$ ano diurno, 17 anos, autodeclarado homem trans e pardo, residente no bairro Mário Quintana), que avalia morar distante da escola, há um reforço à divisão entre centro e periferia como referência de distância: "A escola aqui é quase no centro, eu moro bem na periferia".

Convém apontar que, em quase todos os casos, o uso de linhas de ônibus específicas, as quais circulam no interior dos bairros ou em avenidas próximas às casas dos estudantes, aparece como estratégia de transporte habitual e forma determinante para habitar a cidade e estar na escola. Curiosamente, os estudantes citam os números das linhas de ônibus como marcos de referência espacial e social. No caso de Jonathan (estudante do $2^{\circ}$ ano noturno, 19 anos, autodeclarado homem pardo e residente no bairro Bom Jesus), uma leitura mais adensada acerca da questão pôde ser apreendida. Ao falar das vantagens e desvantagens de morar distante do colégio, sugeriu uma caracterização dos grupos jovens que, comumente, habitam o bairro de sua moradia: 
Onde eu moro, ali, é um bairro pobre. Tem vários amigos meus que já deixaram de vir no colégio porque não tem a passagem. Então, a vantagem de morar perto do colégio é que tu pode ir andando, não vai gastar a passagem. Mas eu escolho aqui porque aqui é um colégio melhor dos que os que tem lá na Bom Jesus. Lá na Bom Jesus tem muitas pessoas que não vão pra estudar. Vão pra causar confusão e briga, tem muito isso lá. Por isso eu prefiro estudar num colégio um pouco mais longe, do que lá (Jonathan).

Nesse trecho, é possível figurar, dentre outras percepções, a ideia de que os custos com a passagem de ônibus emergem como barreira socioeconômica às formas de experimentação da cidade para alguns jovens "periféricos". Mas a justificativa não encerra o assunto. Simultaneamente, a escola fora do bairro de moradia é a opção escolhida para aqueles que possuem a garantia econômica ao meio de transporte, justamente por aglutinar grupos sociais de outras origens numa região central da cidade. Diante do que se percebe, nela, os jovens possuem menos chances de reproduzir ou de conviver com práticas de violência no âmbito escolar, a qual atrapalharia a trajetória dos que "querem estudar".

Este aspecto denota a presença de relações desiguais internas aos bairros periféricos, nas quais alguns estudantes podem ir "estudar fora" e outros não, tendo a necessidade de frequentar as escolas marcadas pelo estigma da criminalidade dos territórios em que estão situadas. É representativo como este projeto de "estudar em um colégio um pouco mais longe" demarca diferenças na diversidade local, compondo-se enquanto um movimento estratégico à ascensão social e de busca por objetivos futuros.

Desta maneira, apesar de ter um colégio situado nas proximidades de sua casa e por já ter frequentado o mesmo, o referido entrevistado optou por estudar no Instituto Estadual Rio Branco, também, por incentivo da própria família: “(...) A minha vó que apoiou pra esta mudança, ela que é nossa responsável". Tal situação alude ao fato de que decisões que envolvem a ascensão socioeconômica, nos casos estudados, não são necessariamente individuais, já que, evidentemente, envolvem uma rede de incentivos (familiares ou de pessoas próximas dos jovens) ${ }^{10}$. Porém, o aspecto econômico em torno do transporte é salientado, sendo que a grande desvantagem é a "passagem cara"11.

${ }^{10} \mathrm{O}$ apoio da família é fundamental para que os jovens tomem a decisão (mais intersubjetiva, familiar e menos individual, portanto) de estudar fora do bairro de moradia. Todos os entrevistados manifestaram a influência da figura materna (mãe, ou vó) em suas escolhas, também porque realizam a sua criação e destinam recursos ao transporte e alimentação. Diante da ausência dos pais, os recursos investidos pela referência materna são centrais, como alude Paulo: "Minha mãe ajuda em tudo, ela me dá a passagem, ou se eu tenho médico, me dá dinheiro pra comer". Situação semelhante ocorre com Joana (estudante do $1^{\circ}$ ano diurno, 16 anos, autodeclarada mulher branca e residente no bairro Rubem Berta) e Ana. Ou, também, como no apoio obtido por Jonathan: "Tudo é por minha conta, mas minha vó ajuda se eu preciso de dinheiro emprestado. Depois que eu recebo, daí eu pago ela".

${ }^{11}$ Em 2018, o valor da passagem unitária de ônibus em Porto Alegre era de 4 reais e 30 centavos. Em 2008, o custo era de 2,10 reais. Ou seja, o custo da passagem mais do que dobrou em 10 anos. Indicadores disponíveis em: <http://lproweb.procempa.com.br/pmpa/prefpoa/observapoa_2011/usu_doc/revista-parte02modal onibus-pg 19-38.pdf>. 
Analiticamente, as respostas não apenas reforçaram perspectivas em torno do tempo e dos custos de deslocamento, mas, para alguns entrevistados, foram meios de comunicar diferenciações entre o local de moradia e o local de estudo, sugerindo que o endereço de habitação está diretamente atrelado aos modos de habitar a cidade e de se viver a juventude. Como forma de elucidar esta afinidade, aponto a seguinte narrativa, evocada por Igor (estudante do $3^{\circ}$ ano noturno, 20 anos, autodeclarado homem negro e residente no bairro Mário Quintana):

(...) A vantagem de morar longe é que a gente não tem o acesso fácil às pessoas que não querem estudar. Dificulta o nosso acesso às pessoas que querem coisa errada na escola. As escolas da Zona Norte, onde me criei no Mário Quintana, tem um acesso maior à criminalidade. E as escolas mais longes da periferia têm difíceis acessos a essas pessoas. E tu 'acaba' conhecendo pessoas e se relacionando com pessoas de fora da comunidade, absorvendo conhecimento de fora e levando conhecimento, fazendo uma troca de conhecimento, no caso. Aqui [escola] temos trocas de conhecimento com pessoas de vários bairros de Porto Alegre. Troca de gírias, estilos, roupas etc.

A dimensão das trocas em torno da produção de identidades jovens é central na resposta acima, mas desperta atenção, também, a relação situada entre o local de moradia e as mencionadas zonas de criminalidade urbana. Assim, morar longe da escola representa a possibilidade de frequentar outras zonas urbanas e de estabelecer redes de trocas simbólicas e relacionais que não estariam associadas ao imaginário social da criminalidade e às práticas ilícitas da violência urbana situada em bairros periféricos.

Outro interlocutor reforçou a ideia de que o "endereço" pode ser visto enquanto um critério de diferenciação social (NOVAES, 2006, p. 106). O estudante assinalou, porém, uma suposta "vantagem" de residir num bairro tido como periférico de Porto Alegre. Nos termos de Jonathan: “(...) Lá dentro, eu não tenho medo de ser assaltado, eu ando livre, mas, às vezes, a gente tem medo de tomar um tiro, porque agora a polícia tem essa mania de invadir as vilas". A inconveniência para ele, por outro lado, pôde ser condensada pela seguinte exposição: "A desvantagem é que por ser um lugar com pessoas carentes é um lugar muito mal visto, entendeu?".

Efetivamente, o "endereço" é um critério definidor das identidades jovens, fazendo diferença em suas relações cotidianas. Como situou Regina Novaes (2006, p. 106), o local de moradia "abona, ou desabona, amplia ou restringe acessos". Em sua visão, a autora situa a emergência de uma "discriminação por endereço", enquanto marcador social que se adiciona ao preconceito geracional e à discriminação de classe, gênero e cor, traduzindo efeitos práticos aos projetos e às possibilidades destinados aos "jovens periféricos". Ainda, situa que, para as gerações passadas, esse critério poderia ser visto diretamente como uma expressão da estratificação social urbana, um indicador de renda, ou de pertencimento de classe.

Com a intensificação da criminalidade em algumas zonas urbanas nas grandes cidades, subjugadas pela violência e pela corrupção de agentes policiais e do tráfico de armas 
e de drogas, certos endereços trazem consigo o "estigma" atrelado a essas áreas urbanas, chamadas de favela, vilas, periferias, comunidades, morros, conjuntos habitacionais, dentre outros nomes que carregam leituras preconceituosas (NOVAES, 2006). Esta dimensão foi apontada, criticamente, Ruan (estudante do $2^{\circ}$ ano noturno, 18 anos, autodeclarado homem branco e residente no bairro Bom Jesus):

As pessoas falam que tudo é culpa da favela, de quem mora na vila. Já aconteceu das pessoas perguntarem: tu mora mesmo na Bom Jesus? Mas tu não tem jeito de quem mora lá. (...) A desvantagem é a visão das pessoas, do crime e criminalidade da cidade. Numa entrevista de emprego me perguntaram: onde tu mora? - Na Bom Jesus (respondi). - Mas tu não tem cara de quem mora na Bom Jesus, parece que tu mora em um bairro mais nobre.. E eu fiquei tipo: gente, como assim?

Objetivamente, as palavras enunciadas pelo interlocutor denunciam a existência de um imaginário social que dificulta o acesso de jovens urbanos, residentes em zonas degradadas pela violência, ao mercado de trabalho, o que pode ser lido pela máxima empregada por Regina Novaes (2006, p. 106): "o jovem que mora em tal lugar de bandidos é um bandido em potencial: melhor não empregar". Ou se ele "mora ali, não vai poder sair para trabalhar quando houver um conflito entre grupos de traficantes ou entre traficantes e a polícia: melhor não empregar".

O que posso perceber, diante do exposto, é que estudar em uma escola situada em uma região central da cidade configura-se enquanto decisão estratégica para reverter o processo de demonização de identidades periféricas ${ }^{12}$ e de reconfigurar os efeitos da "discriminação por endereço", servindo, em alguns casos, como modo de estabelecer referências aos "avaliadores do campo de trabalho". Ao mesmo tempo, sair da zona de moradia à escola, emerge como modo de praticar a cidade e de operar usos táticos dos espaços pelos quais é possível circular na relação entre local de moradia, local de estudo e, em alguns casos, local de trabalho ${ }^{13}$.

\section{QUAIS SÃO AS ESTRATÉCIAS DE MOBILIDADE URBANA E O QUE ELAS COMUNICAM?}

Conforme já assinalado no subtítulo anterior, as estratégias e as formas de mobilidade urbana podem ser definidas em concordância com as atividades praticadas em

\footnotetext{
${ }^{12}$ Ver Wacquant, 2008, p. 33-52.

${ }^{13}$ Importante destacar que a estratégia de estudar em uma escola situada mais próxima à região central da cidade não é engendrada pelos jovens e seus familiares por razões estritamente escolares. Conforme apontei na monografia final, apesar da existência de expectativas de uma melhor qualidade do ensino em escolas não periféricas, o contexto escolar pesquisado apresentava, ao contrário, dificuldades para o seu devido funcionamento, principalmente pela falta de professores efetivos e disponíveis para todas as disciplinas. Como exemplo, relato que cheguei a ministrar aulas na disciplina de Português, mesmo sendo professor na disciplina de Sociologia (FERNANDES, 2019, cap. 3). Isso não significa dizer que a equipe pedagógica e diretiva da escola estudada não estava comprometida em resolver a questão, que depende, contudo, de decisões da gestão educacional estadual.
} 
torno dos locais de moradia, do local da escola e, para alguns jovens, em seus locais de trabalho, além dos espaços de sociabilidade de lazer e entretenimento.

Рara aqueles jovens que trabalham, os deslocamentos pelos espaços urbanos são multiplicados, repercutindo na ampliação de seus repertórios e modos de praticar a cidade geralmente, são os que estão com idade igual, ou superior aos 18 anos. Contudo, ainda assim, alguns deles restringem o deslocamento no circuito casa-trabalho-escola. Nesta pesquisa, cabe destacar que cinco jovens entrevistados e matriculados no ensino médio noturno estavam trabalhando, em estágios, ou pelo programa Jovem Aprendiz, principalmente em empresas estatais. A escolha de muitos estudantes pela matrícula à noite estava vinculada diretamente com seus interesses e atividades profissionais, exercidas durante o dia - uma maneira de se diferenciar e de produzir a transição da adolescência à vida adulta (DAYRELL, 2003).

O principal meio de transporte a todos os entrevistados é o ônibus, o que os atraí para caminhadas breves pela cidade, em direção às paradas, ou, inversamente, dos pontos de descida do transporte coletivo até os seus destinos finais. Mas existe, neste aspecto, a configuração de um traço singular nestes jovens urbanos: a busca por alguma condição inconstante de "nomadismo espacial", mobilidades entre rotas possíveis e rotas evitadas. De fato, trata-se de mobilizar elementos de uma ordem construída, em busca de uma experiência esfarelada no tecido urbano, que é produzido sob o signo de um lugar próprio: a cidade (CERTEAU, 1990, p. 183).

É na cidade que rotas são feitas e desfeitas, a partir das condições de cada meio de transporte. Em geral, o tempo de deslocamento, aos que trabalham e estudam, varia. Em alguns casos, os jovens chegam a passar mais de duas horas do dia no transporte pela cidade (como relatou lgor), sendo que, em outros, o tempo de deslocamento pode chegar a 20 minutos (no caso de Ana, estudante do $1^{\circ}$ ano diurno, 15 anos, autodeclarada mulher branca e residente no bairro Petrópolis) - o que retrata uma desigual distribuição do tempo, além de modos distintos de produzir-se enquanto jovem e de fruir dos serviços que a cidade oferta.

Em relação aos outros meios de transporte, o uso de aplicativos de celular, para a chamada de veículos, é empregado por alguns interlocutores, mas em momentos eventuais, em que estão atrasados ao trabalho, ou em rotas nas quais a tarifa é equivalente à passagem de ônibus. No mais, tal uso se encontra limitado a momentos pontuais de lazer, com amigos e/ou familiares. Em alguns casos, para fazer uso do serviço prestado pelos aplicativos de transporte, os estudantes precisam sair das proximidades de seus bairros, a pé, até avenidas próximas, onde o fluxo de veículos e de pessoas é maior, o que revela uma espécie de segregação espacial regida pela violência. O uso de aplicativos não se vincula ao deslocamento de ida e volta da escola. 
No que se refere aos custos para ir à escola, ou ao trabalho, os jovens que trabalham contam com uma fonte de renda própria, a qual acaba sendo o modo como custeiam os seus trânsitos pela cidade, quando não recebem vale-transporte das empresas. Também, a alguns deles, os benefícios de "TRI-escolar" e "Vou à escola14" aparecem como estratégia de desconto ou de isenção da passagem de ônibus, este último destinado a pessoas com vulnerabilidade econômica.

Por outro lado, os jovens engendram táticas para usar o transporte coletivo a baixo custo: uma delas, relatada por uma docente, remete ao fato comum de estudantes passarem juntos na catraca, após a entrada do ônibus, com a anuência não explícita do cobrador. Contudo, a tática nem sempre tem êxitos, diante da desaprovação dos demais usuários do ônibus, ou dos cobradores e motoristas mais atentos.

Sobre o ato de caminhar, ainda no âmbito da mesma questão, é possível salientar uma visão recorrente entre os interlocutores: a percepção sobre a violência urbana estrutura trajetos e interditos, mas não suprime, em sua totalidade, as gestas ambulatórias. Expressões captadas delatam essa relação:

Eu tenho medo de ser assaltada. Eu gostaria muito de caminhar pela cidade, eu não conheço metade da cidade. Tenho medo de outras coisas, também, não tem só isso hoje em dia. Eu tenho medo, por isso não caminho muito (Vanessa).

Não gosto de caminhar. Eu acho Porto Alegre perigosa (Jonathan).

Gostar de caminhar eu gosto, mas eu caminho com medo de ser assaltado (Ruan).

Para além de residirem no mesmo bairro, as expressões dos interlocutores denotam que o "medo de ser assaltado/a" e o "achar um local perigoso" são duas expressões presentes na produção de subjetividades de jovens em torno de seus vínculos com espaços urbanos. As feições do medo, aqui registradas, demonstram que o imaginário em torno de crimes contra o patrimônio, por exemplo, influencia diretamente na conformação de maneiras de transitar pela cidade, reforçando a ideia de que o modo individual de deslocamento acarreta maiores vulnerabilidades nos itinerários cotidianos. Outra dimensão fundamental é a identificação de experiências de preconceito de classe e de discriminação racial, no caso de jovens negros ${ }^{15}$. A conformação de uma "cultura do medo" aos jovens

\footnotetext{
${ }^{14}$ Benefício concedido pela Prefeitura Municipal de Porto Alegre a alunos de baixa renda e em situação de vulnerabilidade social, prevendo isenção das passagens. Já o cartão "TRI-Escolar" garante o desconto de $50 \%$ na tarifa de ônibus municipal, garantia prevista aos estudantes matriculados na rede pública e privada. Informações em: < https://alfa.portoalegre.rs.gov.br/cartade-servicos/cartao-tri-vou-escola>.

${ }^{15}$ A temática racial não foi enfatizada neste artigo. Contudo, como era de se esperar, alguns interlocutores relataram experiências de discriminação racial pelas quais passaram (foram seguidos no shopping por seguranças; abordagens policiais recorrentes; humilhações e falas racistas de colegas e desconhecidos na escola e na cidade, dentre outros episódios). Logo, além de distinções performadas pelo gênero, há uma diferença na circulação pela cidade entre jovens negros e jovens
} 
urbanos está associada à produção de um repertório simbólico e de táticas singulares, em torno do viver numa cidade violenta (ECKERT, 2002).

De outro modo, a astúcia presente numa imagem que associa certa moratória social à juventude, the atribuindo um tempo para experimentações e relativizações (DAYRELL, 2003), pode ser relacionada com a seguinte perspectiva, dita por um estudante: "Eu caminho bastante e não tenho medo. Tem gente que tem, eu acho isso muito errado". Entretanto, as experimentações são negociadas e avaliadas diante dos receios, riscos e medos em jogo nas dinâmicas da urbe.

Alguns entrevistados manifestaram certo "gosto", desejo e vontade atrelada à possibilidade de praticar o espaço através de seus próprios passos, como na declaração de Paulo: "(...) Eu gosto de conhecer minha cidade. Eu realmente gosto de Porto Alegre. Apesar de ser uma cidade desigual, meio injusta. Mas eu acho uma cidade bonita. Eu gosto de andar. Eu vinha pra escola desde muito novo sozinho". Andar em uma "cidade desigual" tem influência na forma como interlocutor interpreta a sua relação com Porto Alegre, mas isso, a seu ver, não anula uma avaliação tida como positiva da mesma. O deslocamento até a escola, feito desde que era "novo", parece ser central em sua maneira de avaliar.

Importante destacar, ainda, que as estratégias de andança pela cidade não são apenas moduladas pelas espacialidades urbanas, mas também por suas temporalidades: os jovens entrevistaram salientaram horários e períodos mais seguros e propícios para entrar e sair dos seus bairros de moradia, circular por outros percursos e, inclusive, para ir e voltar da escola ${ }^{16}$.

\section{COMO SEUS DESLOCAMENTOS, A PARTIR DA NECESSIDADE DE FREQUENTAR A ESCOLA, INFLUENCIAM AS SUAS PERCEPÇÕES SOBRE A CIDADE HABITADA?}

Como manifestou Michel de Certeau (1990), as modalidades de gestão tecnocrática e de exercício do poder disciplinar - representado pela figura do panóptico, como sugere Michel Foucault (1987) - não encerram ou controlam, na totalidade, as formas astuciosas de observar, transitar e sentir atreladas às trajetórias forjadas no bojo das estratégias científicas, políticas e econômicas que permeiam uma cidade.

\footnotetext{
brancos, conforme indiquei no "capítulo 7" da monografia final (FERNANDES, 2019). O repertório de "medos" aumenta quando os relatos de jovens negros são analisados, sendo mais recorrente a identificação do "medo da bala perdida" e do "medo da polícia", feições insinuadas no bojo da necropolítica contemporânea.

${ }^{16}$ Objetivamente, foi possível notar que existem diferenças na circulação de jovens homens e jovens mulheres. As mulheres priorizam itinerários mais movimentados e andanças acompanhadas com outras mulheres, amigos ou familiares. O relato de uma estudante sobre "ter muito medo de ser assaltada novamente" e estar sozinha é representativo nesta diferenciação de gênero quando se pensa em possibilidades e estratégias de circulação.
} 
As narrativas dos jovens urbanos e as dos docentes envolvidos apresentam elementos que traduzem as suas formas de operar relações na urbe. Inspirado no que propõe Cornélia Eckert (2002, p. 73), o "narrado" pode ser tomado como "a maneira singular de problematizar o caráter temporal das experiências de vida, exteriorizando valores interiorizados cotidianamente pelo sujeito-narrador", o que evidencia variáveis na sua trama de inserção nos contextos sociais, na negociação de papéis e performances e nos desempenhos em torno do ato comunicativo e vivido.

Ao serem questionados sobre "o que mais gostam na cidade", os interlocutores anunciaram as seguintes respostas:

Eu gosto de ficar olhando a cultura, a arquitetura da cidade eu acho bem bonita, coisas assim. Observando a paisagem (Ruan).

Eu gosto de olhar pela janela do ônibus. Olhando os prédios, as placas (Paulo).

Gosto de ver as paisagens. Eu gosto da praça, aqui perto da escola, tem bastante gente, tem cachorro. É bem bonito ali. Gosto de ver as lojas, comércio. E eu gosto de ir pro Centro, minha mãe fala que eu sou louca, mas eu adoro ir pro Centro (Joana).

Eu gosto de prestar atenção na natureza, bastante. Na arte, porque minha mãe é professora de artes e, às vezes, tem um grafite legal (Ana).

Como se apreende, a ocasião de falar sobre aquilo que se "gosta" na cidade é um momento ímpar para se falar sobre si mesmo, de seus gostos, trajetos e estilos desdobrados nas maneiras ordinárias de praticar o espaço urbano. Cabe situar que a ideia de estilo aqui evocada é uma referência não apenas a uma manifestação simbólica das culturas juvenis, que expressa elementos materiais e imateriais que os jovens mobilizam em torno de sua identidade individual e coletiva (DAYRELL, 2003 apud FEIXA, 1998), mas, também, рага pensar a existência de um estilo de percepção, com formas singulares de observar, imaginar e pertencer à cidade que se habita.

Nesta direção, a experimentação urbana passa pelo ponto de vista do olhar, o que sugere a produção de dinâmicas de visibilidade conectadas com espacialidades. Efetivamente, o nomadismo ensejado pelos jovens se desdobra em possibilidades de representar e projetar a si próprio nas relações com o que se observa.

Por outro lado, ao serem questionados sobre "o que menos gostam na cidade", os entrevistados comunicam feições do medo, da insegurança e de uma suposta crise urbana, o que torna paradoxal a relação com o espaço urbano. A existência de tensões em torno do viver numa cidade violenta pode ser identificada pelos jovens narradores:

(...) A minha mãe tem receio de que eu saia sozinho na rua. Também, é muito raro eu sair assim nos lugares estranhos. Algumas pessoas já sabiam que eu era da comunidade LGBT. Mas outras não sabiam e quando souberam pararam de falar comigo, pararam total. Por isso, meu receio maior é quando eu vejo uma pessoa muito preconceituosa, sabe? E eu sou daqueles que passa de cabeça erguida. Meu receio é que aconteça algo comigo e as pessoas que estão a minha volta sofram. Não tenho muito medo por mim, mas tenho medo que eles sofram. (...) Outra coisa que odeio ver na rua é assédio. Tipo, ver um cara 
assediando uma mulher. É uma coisa que eu volto e boto a boca no cara, não 'tô' nem aí, eu falo 'quem tu pensa que tu é? relaxado!' Não 'tô' nem aí (Igor).

(...) O que não gosto é isto: pessoas arrogantes, que não te respeitam. Várias pessoas passam por mim e esbarram em mim, algumas pedem desculpa e outras não. Tipo, lá no meu trabalho, eles se acham melhor porque eu sou apenas jovem aprendiz (Vanessa).

Na rua é a insegurança, medo de ser roubado. Ninguém sabe quem representa uma ameaça (Nathan).

A criminalidade, os lixos jogados na rua, deixam a cidade muito feia, o ar é pesado. Às vezes, eu vou pra praia e sinto bastante quando volto (Ruan).

Não gosto de ir no Centro. Não tem uma boa pavimentação. É sujo e desagradável. Não me sinto bem. Não é seguro, pode ser assaltado, tenho medo, porque me assusto muito rápido (Paulo).

Como é possível analisar, os jovens interlocutores e moradores de Porto Alegre engendram representações e deslocamentos a partir de imprevistos e expectativas reais em torno da experimentação da violência. Nas modalidades de violência apresentadas acima, uma forma recorrente de lidar com a violência urbana é a de considerar o objeto ou sujeito desconhecido como suspeito, como na declaração de Nathan (estudante do $3^{\circ}$ ano noturno, 19 anos, autodeclarado homem branco e residente no bairro Vila Jardim): "ninguém sabe quem representa uma ameaça".

De modo complementar, apreende-se que o medo identificado no grupo estudado é, também, mediado por narrativas e experiências vivenciadas pelos seus pais (ou melhor, suas mães!), irmãos e afins, que de alguma forma exercem influência sobre o nomadismo de seus parentes jovens, mesmo que eles reprovem qualquer forma de controle, ou reconheçam cobranças e orientações dos mais velhos em suas narrativas. Contudo, ainda assim certos riscos são avaliados, aceitos, ou instavelmente vivenciados.

A violência urbana aparece incontestavelmente nas narrativas capturadas e tece significações em torno de formas variadas. Aos interlocutores, algumas são identificadas: a violência contra a orientação sexual, figurada na homofobia; a violência racial contra negros e negras; a violência de gênero e o assédio sexual e moral destinado às mulheres; o preconceito geracional, baseado em hierarquias sociais; a violência patrimonial, na possibilidade de ser assaltado, roubado; a violência na "discriminação por endereço"; os riscos da "bala perdida" (e de sua letalidade); e, pode-se dizer, a violência contra o direito de circular pela cidade, retida no fato de que as "pessoas polvem e sujam", mas também (re)produzem fronteiras de classe, desmobilizando as motivações de fruir as oportunidades e os bens ofertados em certos territórios urbanos.

Em uma cidade dinamizada pela insegurança, emerge como aspecto a ser considerado, em torno das relações dos jovens com e nos interstícios da vida urbana, a produção de uma "cultura do medo", isto é, uma certa modulação simbólica que articula 
representações nas quais o medo aparece com feições e sentidos variados (ECKERT, 2002 apud SOARES et al., 1996, p. 259).

\section{ALGUMAS CONSIDERAÇÕES}

Ao longo deste texto, procurei demonstrar como as relações de jovens, com os espaços que habitam, conectam-se com as suas formas de interpretar e experenciar a cidade e com modos específicos de viver as suas juventudes. Juventudes, no plural, como modo de enfatizar a diversidade de modos existentes de ser e estar jovem (DAYRELL, 2003), os quais possibilitam, em sua observação, a análise em torno de marcadores sociais que influem sobre as suas existências.

Рara iniciar esta pesquisa, o vínculo de estágio docência com o ensino médio foi central. A partir disso, tornou-se possível uma sistematização de experiências desdobradas nas interações com estudantes e professores, no processo de ensino-aprendizagem proporcionado pela disciplina de Sociologia, no ensino público e pela interação extraclasse, no âmbito do Instituto Estadual Rio Branco.

Complementarmente, a pesquisa foi proposta cortejando o esforço de compreensão das formas de interação, dos usos e apropriações do espaço urbano, feitos pelos jovens, seja nos interstícios da vida institucional escolar, ou fora dela - nas maneiras criativas de inventar o cotidiano (CERTEAU, 1990). Assim, busquei elaborar e visibilizar diferentes maneiras de operar e praticar relações com e na cidade, engendradas pela juventude, sobretudo estudantes secundaristas, imersos em seus circuitos e nos repertórios simbólicos e materiais produzidos em torno de suas expressões discursivas, comportamentos e relações sociais.

Como ponto de partida para a problemática de pesquisa, considerei a escola como um espaço central ao estudo, fundamentalmente, porque congrega uma diversidade de "experiências juvenis", sendo vista como um equipamento de referência (PEREIRA, 2010).

Evidentemente, as relações tecidas entre os jovens com e nos espaços urbanos transbordam nas maneiras pelas quais eles coabitam o próprio espaço escolar, que, inversamente, os habilita a transitar estrategicamente pela cidade, lançando mão de táticas específicas, para a realização de diferentes atividades: estudar, trabalhar, transitar, recrear, expressar, flertar, ficar, evitar e desviar, dentre outras.

Nas interlocuções com os jovens, priorizei identificar alguns marcadores sociais que incidem sobre as suas trajetórias; as relações que nutrem com os locais onde moram, estudam e trabalham; as formas e estratégias empregadas de mobilidade; as percepções que engendram ao longo do processo de "praticar a cidade"; e, por fim, suas problematizações, altamente críticas, em torno das tensões e das inseguranças de viver em uma capital. 
Incontestavelmente, a estratégia capturada neste trabalho, ensejada por determinados jovens, de estudar fora das proximidades dos seus locais de moradia, não constitui uma possibilidade para todas as pessoas que residem nas zonas periféricas dos grandes centros urbanos. Torna-se uma maneira objetiva de reinventar sentidos às suas experiências: sejam elas de vitimização, precarização; sejam elas de busca por ascensão.

À luz destas variáveis, categorizadas ao longo do processo de pesquisa, desdobrei como o aspecto nômade, associado a diferentes formas de viver a juventude, aparece como componente presente nas trajetórias analisadas, configurando modos específicos de nomadismo juvenil, isto é, de fluxos relacionais altamente dinâmicos (o que significar dizer que as formas aqui comunicadas não finalizam repertórios de circulação). Notadamente, as narrativas e práticas engendradas pela instabilidade dos movimentos de jovens nos espaços urbanos - mesmo diante de suas redes de vigilância, mecanismos de controle e domínio disciplinar -, revelam maneiras criativas e lúdicas de habitá-lo, configurando o que sugiro nomear de "astúcias juvenis", realizando uma franca apropriação da perspectiva de Michel De Certeau (1990).

Enfatizo, ainda, que a pesquisa procurou evidenciar o quanto certas tensões em torno da insegurança urbana fazem parte da produção de subjetividades jovens na cidade de Porto Alegre, sendo a violência um componente presente nos espaços que habitam, com destaque aos bairros que moram. Experiências distintas de violência e de vitimização ficaram evidentes, entre os seus locais de moradia (nos bairros), local de estudo e centro da cidade. As impressões de pulverização do medo foram constantes.

Neste sentido, os interlocutores manejam narrativas e práticas para tentar lidar com os efeitos da violência e dos discursos em torno dos seus locais de moradia, vistos, em conteúdos midiáticos e nas relações ordinárias, como zonas urbanas marcadas pelo estigma territorial em relação às demais partes da cidade (WACQUANT, 2006). Tal fato demonstra como as segregações espaciais condicionam trajetórias em uma cidade como Porto Alegre. Uma estratégia é evidente: estudar em locais centrais da cidade, permutando sentidos e desestabilizando preconceitos associados às suas existências, como vemos no caso dos estudantes que frequentam o Instituto Estadual Rio Branco.

Situo, portanto, como através da análise de experiências juvenis, a partir de um contexto escolar específico (uma "escola de passagem"), são notabilizadas táticas e problematizações com finalidades circunstanciadas, insinuadas no bojo de uma crise urbana: a busca pela reversão dos estigmas territoriais e, sobretudo, pela denúncia da desigual distribuição da violência na cidade.

\section{REFERÊNCIAS}


AQUINO, Laurence Sanzi. A experiência escolar em tempos de ensino médio politécnico. Dissertação de Mestrado. Universidade Federal do Rio Grande do Sul (UFRGS), Programa de Pós-Graduação em Sociologia. Porto Alegre/RS, 2016.

ARIÈS, Phillipe. História social da criança e da família. Rio de Janeiro: Zahar, 1978.

BARROS, Betina Warmling. A coerência da crueldade: os significados da violência extrema para os envolvidos no tráfico de drogas no Rio Grande do Sul. Dissertação de Mestrado em Sociologia. Instituto de Filosofia e Ciências Humanas (IFCH/UFRGS). Porto Alegre/RS, 2020.

CERTEAU, Michel de. A invenção do cotidiano I: artes do fazer. Petrópolis, RJ: Vozes, 3º ed., 1990.

CIPRIANI, Marcelli. Os coletivos criminais de Porto Alegre entre a "paz" na prisão e a guerra na rua. Dissertação de Mestrado em Ciências Sociais. PUCRS, Porto Alegre/RS, 2019.

DAYRELL, Juarez. A escola como espaço sócio-cultural. In: DAYRELL, J. (org.): Múltiplos Olhares: sobre educação e cultura. Belo Horizonte, UFMG: 1996. p. 27.

40-52, 2003. O jovem como sujeito social. Revista Brasileira de Educação, Rio de Janeiro, n. 24, p.

ECKERT, Cornélia. "A cultura do medo e as tensões do viver a cidade: narrativa e trajetória de velhos moradores de Porto Alegre". In: MINAYO, M. C. S.; COIMBRA JUNIOR, C. E. A. (Org). Antropologia, saúde e envelhecimento. Rio de Janeiro: Editora FIOCRUZ, Antropologia \& Saúde collection, 2002. p. 73-102.

FEIXA, Carles. De jóvenes, bandas y tribus: antropología de la juventud. Barcelona, Ariel, 1998.

FERNANDES, Bruno Guilhermano. Experiências Juvenis e Espaços Urbanos: relações a partir do contexto escolar. Trabalho de Conclusão de Curso - Licenciatura em Ciências Sociais. Instituto de Filosofia e Ciências Humanas (IFCH/UFRGS). Porto Alegre/RS, 2019.

FONSECA, Cláudia. Quando cada caso NÃO é um caso: pesquisa etnográfica e educação. Revista Brasileira de Educação, Rio de Janeiro, n. 10, p. 58-78, 1999.

FOUCAULT, Michel. Vigiar e Punir: 0 Nascimento da Prisão. Petrópolis: Ed. Vozes, 1987.

GOLDMAN, Márcio. Alteridade e experiência: antropologia e teoria etnográfica. Revista Etnográfica, Lisboa, v.10, n.1, p. 159-173, 2006.

MAGNANI, José Guilherme. De perto e de dentro: notas para uma Etnografia Urbana. Revista Brasileira de Ciências Sociais, v. 17, n. 49, p. 11-29, 2002.

Os circuitos dos jovens urbanos. Revista Tempo social, São Paulo, v. 17, n.

2, p. 173-205, 2005.

MOREIRA, Antônio Flávio B.. Sociologia do Currículo: origens, desenvolvimento e contribuições. Em Aberto, v. 9, n. 46, p. 156-167, 1990. 
NOGUEIRA-RAMÍREZ, Carlos Ernesto. Pedagogia e governamentalidade, ou da Modernidade como Sociedade Educativa. Belo Horizonte: Autêntica Editora. Coleção Estudos Foucaultianos, 2011.

NOVAES, Regina. Os jovens de hoje: contextos, diferenças e trajetórias. In: ALMEIDA, Maria Isabel Mendes de; EUGENIO, Fernanda (Org.). Culturas Jovens: novos mapas do afeto. Rio de Janeiro: Zahar, 2006. p. 105-120.

OLIVEIRA, Amurabi; BOIN, Felipe; BÚRIGO, Beatriz D. Quem tem medo da etnografia? Revista Contemporânea de Educação, v. 13, n. 26, p. 10-30, 2018.

PAIS, José Machado. Máscaras, Jovens e "Escolas do Diabo". Revista Brasileira de Educação, v. 13 ก. 37, p. 7-37, 2008.

PEREIRA, Alexandre Barbosa. "A maior zoeira": experiências juvenis na periferia de São Paulo. Tese (Doutorado em Antropologia Social). Faculdade de Filosofia, Letras e Ciências Humanas da Universidade de São Paulo, São Paulo/SP, 2010.

"Do controverso "chão da escola" às controvérsias da etnografia: aproximações entre antropologia e educação". Horizontes Antropológicos, Porto Alegre, v. 23, n. 49, p. 149-176, 2017.

SCHWEIG, Graziele Ramos. Aprendizagem e ciência no ensino de Sociologia na escola: um olhar desde a Antropologia. $1^{\circ}$ ed. - Porto Alegre: Cirkula, 2015.

SEFFNER, Fernando. Escola pública e professor como adulto de referência: indispensáveis em qualquer projeto de nação. Educação Unisinos, v. 20, n. 1, p. 48-57, 2016.

SOARES, Luís Eduardo. et al. Violência e Política no Rio de Janeiro. Rio de Janeiro: Relume-Dumará, Iser, 1996.

WACQUANT, Loïc. A estigmatização territorial na idade da marginalidade avançada. Sociologia, Revista da Faculdade de Letras da Universidade do Porto, v. 16, p. 27-39, 2006. As duas faces do Gueto. São Paulo: Boitempo, 2008.

WILLIS, Paul. Aprendendo a ser trabalhador: escola, resistência e reprodução social. Porto Alegre: Artes Médicas, 1991. 